\title{
AOR
}

Selected Papers of \#AolR2020: The $21^{\text {st }}$ Annual Conference of the Association of Internet Researchers Virtual Event / 27-31 October 2020

\section{DIGITAL GENDER DISIDENTIFICATIONS: QUEER MIGRANTS AND TRANSNATIONAL CULTURES OF GENDER DIVERSITY}

Lukasz Szulc

University of Sheffield

The twenty-first century has observed the emergence of new practices of gender diversity, which eschew rigid gender binary and proliferate new gender labels, including "nonbinary," "genderfluid," and "agender." Time magazine declared the year 2014 as "the transgender tipping point" (Steinmetz, 2014), recognizing not only the growing visibility of trans people, especially in the mainstream media in the US (Cavalcante, 2018), but also emerging practices of gender diversity. Reflecting on this emerging gender diversity, a long-standing trans academic and activist Riki Wilchins (2017) asks in a commentary to The Advocate "Is trans over?" Wilchins (2017) suggests that older discourses around transgender, often related to the right to change sex or have one's correct gender recognized, are becoming insufficient for the contemporary discussions about gender, anticipating that "[w]e are unconsciously and finally treading toward the end of gender."

While Wilchins may be correct in forecasting the end of gender as we know it, gender as such has proved to become in recent years a prolific terrain of social experimentation, especially in digital cultures of young people. Numerous researchers point to the key role of online social networks, particularly on Tumblr, for providing unique conditions to explore, articulate and discuss new gender and sexual identity labels (e.g. Byron et al., 2019; Cover, 2018; Haimson et al. 2019; Oakley, 2016; Vivienne, 2017). Large social media platforms have followed suit and incorporated new labels into their interfaces, starting with Google+, which added a third gender option "other" in their sign-up page in 2011, and followed by, for example, Facebook and OKCupid, which provided a long list of predefined gender options in their registration interfaces in 2014 (Bivens \& Haimson, 2016; Cover, 2018). Some key academic discussions on this topic are structured around the questions of subversion and hegemony. While some authors point out that digital gender diversity subverts the hegemonic gender binary (e.g. Haimson et al. 2019; Vivienne, 2017), others argue either that the change is not radical enough (e.g. Oakley, 2016; Schudson \& van Anders, 2019; Webster, 2019) or that there is no change at all, as the proliferation of gender and sexual labels re-establishes existing hegemonies, especially the idea of coherent, authentic, and essentialized gender and sexual identity (Cover, 2018).

Suggested Citation (APA): Szulc, L. (2020, October). Digital Gender Disidentifications: Queer Migrants and Transnational Cultures of Gender Diversity. Paper presented at AolR 2020: The $21^{\text {th }}$ Annual Conference of the Association of Internet Researchers. Virtual Event: AolR. Retrieved from http://spir.aoir.org. 
In this paper, I contribute to this discussion by challenging the dichotomy of subversion versus hegemony, as well as some other related dichotomies of empowerment versus disempowerment or resistance versus regulation. I draw on the concept of disidentification, introduced by José Esteban Muñoz (1999), who argues that attempting to break free of the hegemonic ideology is utopic. Muñoz $(1999$, p. 11) proposes disidentification as "a strategy that works on and against dominant ideology," transforming hegemonies from within. Empirically, I build on the results of a larger project with a diverse group of queer migrants, Polish LGBTQs in the UK, which includes 767 online survey responses and 30 in-depth face-to-face interviews. The survey ran online from mid-August to mid-September 2018 and was promoted through multiple channels, including social media platforms of LGBTQ and migrant organizations, private messages on the biggest Polish LGBTQ website, Queer.pl, targeted advertising on Facebook and Instagram, as well as Twitter posts with the popular hashtag \#PolesinUK. Thirty interviewees were recruited out of 334 survey respondents who stated that they would like to participate in a face-to-face interview. All interviews were semi-structured and were conducted at the end of 2018 or the beginning of 2019 in places chosen by the interviewees, usually at their homes or in cafés. Interviews lasted two hours each on average and were carried out in Polish, with some interviewees switching between Polish and English occasionally.

For the purpose of this paper, I analyze interviews with six participants who identify outside the hegemonic gender binary. My focus on queer migrants helps to bring up the issue of context, particularly cultural and linguistic context, which is largely absent from the current literature on digital gender diversity, dominated by research embedded in English-language countries (US, UK, and Australia). The main contribution of the paper is to reveal the abundant practices of digital gender disidentifications, which I categorize into 1) strategic disidentifications (disidentifying instrumentally for different reasons, e.g. to protect oneself against microaggressions or dumbing down one's identifications to remain intelligible), 2) contextual disidentifications (disidentifying differently in different contexts, e.g. on different social media platforms or when using different languages), and 3) doubtful disidentifications (disidentifying as a result of questioning identifications, e.g. questioning one's right to a particular identification or questioning the finality of one's identification). Such a classification exercise, not intended to create a comprehensive model of disidentifications, allows me to systematize diverse practices of disidentifications, which helps to update the concept of disidentification to digital gender diversity. It also points to the wide spectrum of disidentification practices, suggesting that complicated practices of disidentifications are more prevalent than simple identifications or counteridentifications, at least for marginalized subjects who cannot easily identify with dominant ideologies, in this case the hegemonic gender binary.

\section{References}

Bivens, R. \& Haimson, O. L. (2016). Baking gender into social media design: How platforms shape categories for users and advertisers. Social Media + Society.

Byron, P., Robards, B., Hanckel, B., Vivienne, S., \& Churchill, B. (2019). "Hey, I'm having these experiences": Tumblr use and young people's queer (dis)connections." International Journal of Communication 13: 2239-2259.

Cavalcante, A. (2018). Struggling for ordinary: Media and transgender belonging in everyday life. New York: NYU Press. 
Cover, R. (2018). Micro-minorities: The emergence of new sexual subjectivities, categories, and labels among sexually diverse youth online. In: Susan Talburt (ed.) Youth sexualities: Public feelings and contemporary cultural politics, Santa Barbara, CA; Praeger. pp. 279-301.

Haimson, O. L., Avery Dame-Griff, Elias Capello \& Zahari Richter (2019) Tumblr was a trans technology: the meaning, importance, history, and future of trans technologies. Feminist Media Studies, pp. 1-17.

Muñoz, J. E. (1999). Disidentifications: Queers of color and the performance of politics. Minneapolis: University of Minnesota Press.

Oakley, A. (2016). Disturbing hegemonic discourse: Nonbinary gender and sexual orientation labelling on Tumblr. Social Media + Society, July-September, 1-12.

Poole, R. J. (2017). Towards a queer futurity: New trans television. European Journal of American Studies, 12(2), 1-23. DOI: 10.4000/ejas.12093.

Schudson, Z., \& van Anders, S. (2019). 'You have to coin new things': sexual and gender identity discourses in asexual, queer, and/or trans young people's networked counterpublics. Psychology \& Sexuality, 10(4), 354-368.

Steinmetz, M. (2014, May $\left.29^{\text {th }}\right)$. The transgender tipping point. Time. https://time.com/magazine/us/135460/june-9th-2014-vol-183-no-22-u-s/

Vivienne, S. (2017). "I will not hate myself because you cannot accept me": Problematizing empowerment and gender-diverse selfies. Popualr Communication, 15(2), 126-140.

Webster, L. (2019). "I am I": Self-constructed transgender identities in internet-mediated forum communication. International Journal of the Sociology of Language, 2019(256), 129-146. 